Community Destination Branding: Potential and Paradox

Samantha Murdy and Matthew Alexander

University of Strathclyde Department of Marketing

Paper presented at the 2015 Academy of Marketing Science World Marketing Congress 


\section{COMMUNITY DESTINATION BRANDING: POTENTIAL AND PARADOX}

\section{Introduction}

For destinations to compete in a context of global competition they rely on their destination image as a way to position themselves and resonate with prospective visitors (Di Marino, 2008). As such, the branding of destinations is an important strategy to implement, allowing differentiation between competitors, and providing a competitive advantage. Once branded, it is far easier for a prospective visitor to remember, as well as to form positive perceptions and emotional connections with a destination (Agres \& Dubitsky, 1996; de Chernatony \& McDonald, 2003). The image of the destination is created in part through the identity of the community. However, many small communities struggle to make their voices heard (Taylor, 1995), and in some instances do not feel as though they are competing amongst other small neighbouring communities (TDM, 2014). Given that the level of esteem that a city, or community's name "evokes has a direct impact on the health of its tourism, economic development, prestige, and respect" (Baker, 2012, p. 19) active community involvement in destination branding is potentially an omission from the literature.

\section{Literature review}

Discussion related to community members within destination branding literature has previously been limited to their involvement in the development of the overall brand (see Mayes, 2008; Morgan, Pritchard \& Piggott, 2003). More specifically, Zouganeli, Trihas, Antonaki and Kaldou (2012) explored the use of residents' opinions, using focus groups and questionnaires, to position a destination. However, there has been little discussion of the involvement of community members who actively, and voluntarily, brand their destination.

Despite longstanding efforts to move community based initiatives more to the centre of tourism planning (Hall, 2008; Jamal and Getz, 1995; Murphy, 1985) research on community involvement in tourism activities can often result in pessimistic conclusions. Concerns are usually centred on efforts to involve communities which are driven by multi-national corporations and, as such, are largely top-down processes (Nunkoo et al., 2012). In these cases only lip service is paid to involving local residents in planning (Cole, 2006) and as such community involvement may suffer from tokenism (Timothy, 2007). Alternatively, doubt is also placed on the ability of communities to make a valuable contribution (Aas et al., 2005; Campbell, 1999; Simmons, 1994) or the lack of cohesion within communities (Burns 2004; Simpson, 2008).

Recent work identifies a need for local community involvement beyond established organisational boundaries so that tourism can be integrated into a broader and more complete range of community objectives. This can both ensure that community culture and heritage is preserved (Teo and Yeoh, 1997) and the needs of all relevant stakeholders considered (Burns, 2004). Hamilton and Alexander (2013) suggest that success can be achieved through a more organic co-created approach where communities are given the freedom to develop their own identities. However much of the research within this area focuses on community involvement in discrete projects and not on the wider community role in the branding of a destination. 


\section{Methodology}

This study focuses on a case study of a town in the highlands of Scotland - Pitlochry. In line with well-established case study methods and procedures (Yin, 2003), multiple methods of data collection were utilised including interviews, observation and documentary analysis. Indepth interviews were undertaken with residents of the community (both involved with, and not involved with, the branding of the destination). Interview participants were selected on the basis of their involvement in a wide range of tourism activities with varying degrees of community involvement. Participant and non-participant observation at various tourist attractions and sites and documentary analysis (including analysis of photographs) were also conducted.

\section{Setting the scene: Pitlochry}

Pitlochry is a small town located on the River Tummel within the Perth and Kinross county of Scotland. The region first gained popularity after a visit by Queen Victoria in 1842. Given her favourable opinion of the region and ability to transform the fortune of a destination with a single mention the town became increasingly popular, and a train station was built in 1863 enhancing the levels of tourism (David, 2009). With a population of approximately 2,500 the town remains reliant on the income generated by tourism. The town is known for its community activism (in particular through its flowers), and in both 2009 and 2013 was awarded a gold medal in the Britain in Bloom competition, as well as winner in the small town category (2009) (Pitlochry in Bloom, 2014). The Pitlochry "brand" is promoted through the pitlochry.org website by the Pitlochry Partnership - a community driven organisation. The Pitlochry Partnership was developed in 2007 to assist in the promotion of not only the town as a whole, but businesses by allowing them to join as members. Other community based tourism activity includes: 'Pitlochry in Bloom' a group who organise floral displays, flower beds, hanging baskets and litter pickups around the town; 'The Pitlochry Station Bookshop' which serves the many tourists and visitors to the town raises money for charity and is run by volunteers; and 'The Enchanted Forest' which is an Autumn festival where a local area of woodland is transformed through lighting, sound and visual effects.

\section{Findings}

Four overall themes were identified within the data collection: the Pitlochry brand, community engagement, motivations, and funding. The Pitlochry brand explored the community driven promotion of the destination. Community engagement consisted of four sub-themes: taking ownership, free riders, surrogate council, and succession planning. Motivations consisted of two sub-themes: satisfaction and business success. Funding revolved around the need to compete for funding and fundraise to ensure the projects could continue. All of these themes revolved around the need to enhance the beauty and liveability of the town, and a benefit of this is the increased visitation. As one participant stated: "Tourism is Pitlochry's life blood".

\section{The Pitlochry brand}

The "brand" was referred to by three of our participants, all of whom were members of the Pitlochry Partnership. The brand was discussed overall, as well as the promotional slogan: "Four seasons. More reasons". Community development of the brand was achieved through the adoption of a bottom-up approach to planning. Given the lack of council involvement residents of the community felt the responsibility to promote the town and their involvement 
resulted in the creation of a volunteer organisation which serves in place of a traditional destination marketing organisation (DMO). It was described as an organisation:

“...that represents the businesses of Pitlochry and looks at mainly how we market ourselves as 'Brand Pitlochry' to wider Scotland and beyond. How we drive footfall to Pitlochry and how we ensure businesses flourish and do as well as they can in Pitlochry”.

The main focus of the partnership is its website as participants felt that this could channel visitors and potential visitors better than other more traditional methods. Participants discussed the creation of the branding slogan - one committee member had suggested it, and it had evolved from there. The main objective of the slogan was to extend the tourist season beyond the traditional spring and summer months. Advertisements, in the form of posters developed by local school children (see figure 1 for example), with the pitlochry.org address and the slogan had been placed at the railway station with the aim of encouraging tourists passing through to consider Pitlochry as a tourist destination.

Figure 1: Pitlochry Partnership advertisement

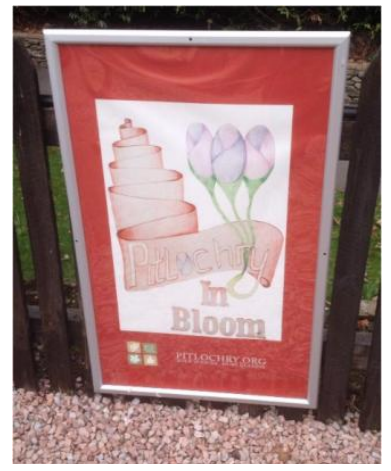

\section{Community engagement}

\section{Taking ownership}

It was outlined that the aim of community projects was to not only beautify and enhance the town, but to get residents to "take ownership" of their community. By taking ownership they were seen as enhancing the pride felt in the town, and benefits might therefore be seen across a number of areas including liveability but, critically, tourism. One of the volunteers interviewed felt that the creation of these groups had let to "a lot of social engagement", while one of the key actors in the development of the Pitlochry brand felt it ignited an enhanced "sense of community".

\section{Free riders}

A free rider problem has been discussed previously in relation to organisations (Grossman \& Hart, 1980) and unions (Booth, 1985). A free rider problem becomes apparent when a group is formed to lobby for and provide a good which is of benefit collectively to all members, yet some enjoy the benefits without incurring any of the costs (Booth, 1985). Our participants identified this issue, stating that although the town as a whole benefited it was a result of the work of only a few active members who had collectively formed groups to promote or beautify the town:

"10\% of the available personnel in Pitlochry are the people that do the work that needs to be done. There's a lot of other people that don't do anything". 
This free rider issue was observed in a number of ways. Some local businesses refused to contribute to a fund for hanging baskets, others objected to bunting hung up along the high street for special events. Our participants who play an active role in the partnership felt that membership of these groups resulted in the label of "busy bodies" given to them creating negative perceptions from some community members.

\section{Surrogate council}

Given council cutbacks other groups had been developed throughout the town, for example, one group was developed to clean up the local paths. Subsequently, given their prominence and presence within the community, several of these groups were contacted by members of the community to address additional issues within the town which should have been addressed by the local authority, such as grass cutting:

"We get all sorts of requests from you know, this kerb it could be beautified or the lampposts are looking in need of repair and the council isn't going to get around to it why don't you do it? And so a lot of the challenge is trying to manage people's expectations of what the Partnership is there for".

Pitlochry Partnership members were concerned that their activism somehow "makes people lazy" and over reliant on voluntary groups. In line with this another interviewee mentioned that while there were a variety of issues directed to them by the community, they "used to try and do too much" and now needed to focus primarily on the promotion of the town, encouraging people to visit.

\section{Succession}

Many of the participants spoke of the need to have leadership, with one commenting that you need to have "the right person who steps up; the right people in charge". Some expressed concerns about what would happen once a key member involved decided to give up or take on a reduced role. The problem of finding someone suitably motivated as a successor was touched upon by several participants. Succession planning is generally discussed when considering family businesses (Sharma, Chrisman \& Chua, 2003). However, this was deemed important as much of the community based tourism activity in Pitlochry is undertaken by a smaller group of highly motivated members.

\section{Motivations}

Satisfaction

Volunteers discussed their involvement with the community groups, with one stating it was "good for the soul". The aim was to get "pleasure out of it" as well as a "feel good factor". Overall, there was strong participation across the groups to promote Pitlochry because it assisted in improving the town, and provided satisfaction to both residents and visitors.

\section{Success of own business}

While more general satisfaction was identified by some participants, one suggested that if there was nothing in it for him he would be less likely to contribute. He owned a local business which benefited from an increase of tourism to Pitlochry, and his motivation to contribute was tied to enhancing the town overall to encourage these visitors:

"I wouldn't do a lot of the stuff I did if I didn't get financial benefit of it myself. The more the town prospers the more people ring me up and want to stay at my guest house". 
Many of the community volunteers were small business owners whom were reliant on tourism, suggesting this was a key motivating factor to the development of the group and, in turn, the town.

\section{Funding}

As a community driven organisation, small businesses were given the opportunity to pay a membership fee which entitled them to promotion within the website used to promote the town. However, some business owners were not happy with this opportunity as they were unable to see the contribution that was being made to the town and, more specifically, their own businesses. In addition, small business owners were asked for donations toward events and projects which would help encourage tourists to visit the town, such as the hanging baskets or the winter lights. However:

"...not everybody contributes. And yet the frustrating thing is the people who pay for it get the benefit and the people that don't, don't pay anything, and get the full benefit of it".

As such, given the voluntary nature of the residents and the reliance on funding and donations, funding for community projects was also attained through the submission of grants. Fundraising was also undertaken by the voluntary members with activities such as morning teas or selling strawberries. It enabled money to be raised by the community to assist in the further development of certain activities to beautify the town. This, in turn, was hoped to increase the level of tourist visitation to the community.

\section{Discussion and Conclusion}

Community involvement in destination branding presents a paradox. Our case suggests that on one hand community involvement can create many benefits for a community including increased tourism visits; increased satisfaction of residents and visitors and; a more focused branding effort created through a bottom-up process. However, community involvement is not without sacrifices particularly, in our case, considerable time and effort by a few committed individuals. There is also evidence here of both free rider, funding and sustainability problems which may dissuade other communities from embarking on similar programmes.

The funding of tourism at a community level is problematic for national governments in a challenging economic climate and the temptation is to focus efforts on the outward facing aspect of destination marketing. Our study suggests that value can be gained by empowering smaller communities to take increased ownership of destination branding but handing over complete control may lead to sustainability problems and lead to a lack of continuity. Unlike previous studies where success can be gained in smaller discrete projects (e.g. Hamilton and Alexander, 2013) our study suggests the community destination branding may be more of a challenge.

\section{References}

References are available upon request. 